\title{
Mapa conceitual: \\ seu potencial como instrumento avaliativo
}

\author{
Nadia Aparecida de Souza* e Evely Boruchovitch ${ }^{* *}$
}

Resumo: Os instrumentos avaliativos são numerosos; dentre eles, o mapa conceitual é uma das alternativas. Entretanto, cumpre questionar: quais as vantagens e as limitações do mapa conceitual como instrumento avaliativo? Assim, o presente trabalho objetivou delinear e analisar as vantagens e as limitaçôes inerentes ao uso do mapa conceitual como instrumento avaliativo. A pesquisa privilegiou a abordagem qualitativa, na forma do estudo de caso. Desenvolvido durante o primeiro semestre de 2006 com 32 alunas do $3^{\circ}$ ano de um curso de Pedagogia de uma universidade pública paranaense, o estudo utilizou questionário, entrevista e observação para a coleta de dados. A análise de conteúdo clássica facultou determinar as aprendizagens decorrentes da vivência, bem como a incidência de diferentes aspectos enunciados como facilitadores ou limitadores na utilização do mapa conceitual como instrumento avaliativo. Estes foram analisados não como antagônicos, mas como facetas de um mesmo fenômeno e, por isso, complementares e interdependentes.

Palavras-chave: avaliação da aprendizagem; formação de professores; práticas avaliativas; mapa conceitual.

\section{Conceptual map: its potential as an assessment instrument}

Summary: There is a great variety of instruments to assess learning. Conceptual maps are questioned in this text, as one of these possibilities. The objectives of this study are to identify and analyze the advantages and limitations inherent to the use of conceptual maps as assessment instruments. In the study, especially the qualitative approach is used in a case study. It was carried out during the first semester of 2006, involving $323^{\text {rd }}$-year students of a pedagogy course at a public university in the state of Paraná. The research was based on a questionnaire, an interview and observation for data collection. The analysis of the material allowed us to determine the actual learning emerging from the experience, as well as the incidence of different aspects which might have facilitated or hindered the use of conceptual maps as assessment instruments. These aspects were analyzed, not as opposites, but as complementary and interdependent facets of the same phenomenon.

Key words: learning assessment; teachers' formation; assessment practices; conceptual map.

\footnotetext{
* Professora do Departamento de Educação da Universidade Estadual de Londrina, PR, Brasil. nadia@uel.br

* Professora do Departamento de Psicologia Educacional da Faculdade de Educação da Unicamp, Campinas, SP, Brasil. evely@unicamp.br
} 


\section{O começo...}

No decorrer das últimas décadas o foco da avaliação tem se ampliado, deixando de evidenciar apenas o produto da ação educativa para contemplar, também, o processo de aprendizagem. A mudança não ficou adstrita ao campo teórico, conquistando espaço no cotidiano das salas de aula, traduzindo uma ressignificação do processo de ensino e aprendizagem - principalmente face ao reconhecimento de que os educandos possuem potencialidade não só para aprender, mas para aprender a aprender e tornarem-se responsáveis pela própria aprendizagem.

Ao compreender o ensino como mais que a mera transmissão mecânica e linear de conteúdos curriculares, os professores têm avançado na construção de uma avaliação da aprendizagem que, afastando-se das veredas limitadas pelas respostas certas e pelas verdades incontestáveis, pelas medidas padronizadas e pelas hierarquias de excelências, tem buscado aproximar-se de um sentido outro: a interpretação das informações coletadas nas práticas avaliativas, tendo por fundamento o diálogo entre os envolvidos e a reflexão compromissada com o aperfeiçoamento do ensino e da aprendizagem.

Avaliar é uma necessidade no contexto escolar. Não para excluir ou estigmatizar, mas para desvelar a "[...] forma como o aluno aprende, sem descuidar da qualidade do que aprende” (Álvarez Méndez, 2002, p.19), de maneira a permitir ao docente ajustar o trabalho pedagógico, promovendo desafios e tarefas que resultem em aprendizagem, em superação de dificuldades. Talvez por isso, o processo seja tão ou mais importante do que o produto, já que a tomada de consciência das formas e dos percursos de aprendizagem empreendidos pelos educandos possibilita aos professores delinearem alternativas mais adequadas para ajudá-los.

Entrementes, para compreender a efetividade do ensino e identificar os problemas de aprendizagem, as práticas avaliativas precisam ser diversas daquelas antes privilegiadas, porque, mais que o domínio de informações ou a aquisição de habilidades, é importante mapear as relações e as conexões produzidas pelo educando para a apropriação e a retenção dos saberes. Para tanto, torna-se fundamental a busca por "observáveis", ou seja, é essencial a consecução de processo de levantamento de informações para escolha dos instrumentos que permitirão recolher dados fundamentais na evidenciação das aprendizagens já edificadas e daquelas ainda em curso (Hadji, 2001).

Os instrumentos avaliativos são numerosos, e as possibilidades de utilização que oferecem variam conforme seus propósitos e suas características. O mapa conceitual é apenas uma das alternativas para a promoção de uma avaliação mais comprometida com a aprendizagem e o desenvolvimento do edu- 
cando, conforme evidenciam diferentes estudos (Otsuka et al., 2002; Araújo; Menezes; Cury, 2003; Sakaguti, 2004; Barbosa et al., 2005;). Entretanto, cumpre questionar: quais as vantagens e as constrições do mapa conceitual como instrumento avaliativo? Responder esse questionamento demandou a enunciação de objetivo geral: delinear e analisar as vantagens e as limitações inerentes ao uso do mapa conceitual como instrumento avaliativo sob a ótica dos alunos, diligentemente perseguido e traduzido em ações específicas e subsequentes.

$\mathrm{Na}$ elaboração da resposta pela consecução da meta estabelecida, aprendizagens diversas daquelas buscadas foram obtidas. Tornou-se possível determinar, também, aprendizagens edificadas pelas participantes no decurso da presente pesquisa. $\mathrm{O}$ trajeto percorrido é apresentado e concomitantemente analisado, considerando dois eixos: (a) aprendizagens edificadas e (b) vantagens e limitações identificadas.

\section{O caminho...}

O estudo privilegiou a abordagem qualitativa da realidade, principalmente porque o interesse principal residiu em questões inerentes à prática escolar cotidiana e ao "[...] redimensionamento do saber e do fazer docentes", pela investigação das "[...] ações e relações que configuram o dia-a-dia da sala [...]" (André, 1995, p. 7). A forma particular eleita para efetivação foi o estudo de caso, pois buscava-se o desvelamento e a compreensão em profundidade de situação: concreta, real, específica, complexa e em efetivação.

O estudo foi desenvolvido no decorrer do primeiro semestre de 2006, com as 32 alunas integrantes do $3^{\circ}$ ano de um curso de Licenciatura em Pedagogia de uma universidade estadual paranaense, turno vespertino. A semestralidade decorreu da blocagem da disciplina de Fundamentos da Alfabetização. Para sua efetivação, os participantes anuíram, firmando termo de consentimento livre e esclarecido.

Após a conclusão das vivências com o mapa conceitual, foi apresentado um questionário exploratório a ser respondido pelas alunas organizadas em dezesseis duplas. Definindo como mínimo a expressão de três itens como resposta, as questôes propostas foram: (a) Quais as principais aprendizagens decorrentes da elaboração do mapa conceitual?; (b) Quais as principais possibilidades inerentes à elaboração do mapa conceitual como instrumento avaliativo?; e (c) Quais as principais dificuldades inerentes à elaboração do mapa conceitual como instrumento avaliativo?

Afora o questionário, cujo objetivo principal era a promoção de um levantamento preliminar de informaçôes, a coleta dos dados deu-se pela utilização de 
outros instrumentos também adequados à abordagem e à configuração do estudo: entrevista semiestruturada e observação direta da realidade.

As entrevistas semiestruturadas foram elaboradas com base nas informações prestadas nos questionários e realizadas com 8 alunas (25\%). A escolha foi aleatória, uma vez que o convite foi feito a todas, mas as participaçóes resultaram da maior disponibilidade de tempo de algumas estudantes. As entrevistas foram gravadas e imediatamente transcritas para que nenhuma informação fosse perdida. Na verdade, as entrevistas possibilitaram o aprofundamento de aspectos apenas enunciados nos questionários.

As observações ocorreram no dia a dia da sala de aula e estenderam-se ao longo do semestre letivo, quando as atividades envolvendo a construção de mapas conceituais eram propostas e levadas a termo, tendo por base os textos a serem lidos e apropriados no decurso da disciplina Fundamentos de Alfabetização. Ações e reações foram descritas, assim como o teor de discussões e análises foram registrados.

As informaçōes coletadas foram organizadas e submetidas à análise de conteúdo clássica, pois "[...] culminam em descrições numéricas de algumas características do corpus do texto [...]", sem desconsiderar "[...] tipos, qualidades, e distinções no texto, antes que qualquer quantificação seja feita" (Bauer; Gaskell, 2002, p. 190). A análise do material textual coletado possibilitou esboçar "[...] uma ponte entre o formalismo estatístico e a análise qualitativa dos materiais" (Bauer; Gaskell, 2002, p. 190). A leitura sistemática e reiterada de todo o material facultou determinar as aprendizagens decorrentes da vivência, bem como a incidência de diferentes aspectos enunciados como facilitadores ou dificultadores na utilização do mapa conceitual como instrumento avaliativo.

\section{Algumas revelações...}

As salas de aula são, geralmente, um locus especial para a transmissão da herança cultural. Muitos professores - talvez por isso - pensam que seu trabalho se limita à exposição dos conteúdos em uma abordagem mais diretiva. Aprender envolve mais, pois encerra o domínio de conceitos, habilidades e atitudes em uma perspectiva de formação plena do ser humano. Aprender significativamente, conforme Ausubel, Novak e Hanesian (1980, p. 159), ocorre quando "[...] uma informação nova é adquirida mediante um esforço deliberado por parte do aprendiz em ligar a informação nova com conceitos ou proposições relevantes preexistentes em sua estrutura cognitiva”. Assim, quando uma aprendizagem é significativa, ela tem o poder de gerar alteraçôes na estrutura cognitiva daquele que aprende, mudando os conceitos preexistentes e formando novas ligaçôes entre eles, envolvendo, em decorrência, o compromisso de 
fortalecer a capacidade dos estudantes não só de aprender, mas também de aprender a aprender, constituindo-se uma meta educacional relevante a ser alcançada nos dias de hoje (Boruchovitch, 1993, 2006; Bronson, 2000).

Em consequência, não somente as informações apresentadas são importantes para a formação dos educandos, mas também as formas de ação e de interação proporcionadas no decorrer do processo, até porque "[...] a intervenção educativa precisa de uma mudança de ótica substancial, na qual não somente abunde o saber, mas também o saber fazer, não tanto o aprender, como o aprender a aprender" (Martinez-Mut; Garfella, 1998, p. 127).

\section{I. Situando as aprendizagens...}

O trabalho com mapas conceituais - como instrumento avaliativo -, diferentemente dos "[...] exames de verdadeiro-falso ou de múltipla escolha [que] não conseguem examinar mais do que uma pequena parte dos conhecimentos relevantes na instrução" (Novak, 2000, p. 192) propiciou às alunas mostrarem como organizaram os conhecimentos, bem como favoreceu-lhes diversas aprendizagens, que, ultrapassando a esfera das temáticas abordadas como conteúdos de ensino, abarcaram aspectos outros: enfocar o essencial, privilegiando os conceitos-chave; hierarquizar ideias, estabelecendo relaçôes significativas entre elas, sedimentando e integrando conteúdos; favorecer a negociação de significados e formas de estruturação; possibilitar síncrese-análise-síntese.

Aprender a identificar, no todo, informações mais relevantes e essenciais foi o aspecto indicado por todas as 16 duplas respondentes, evidenciando o reconhecimento de que, ao longo do processo escolar, foram privadas da possibilidade de aprender a proceder a leituras que favorecessem a identificação das ideias principais e a determinação subsequente dos conceitos-chave. Uma das alunas, na entrevista, afirmou:

Muitas vezes, as dificuldades que enfrentamos no ensino superior são apenas reflexos das dificuldades que temos para ler e, de fato, compreender um texto. O trabalho com mapas conceituais nos levou a aprender a identificar os elementos essenciais e inter-relacionálos. Esse foi um ganho imenso! (A8) ${ }^{1}$.

No contexto escolar, predominam a leitura-informação e a leitura-avaliação. Na primeira, a leitura visa à localização de resposta a questôes - geralmente óbvias e pouco exigentes - pelo aluno, "[...] bastando-lhe ter o olhar treinado para localizar, nos parágrafos, a palavra ou a passagem que responde às

1. As manifestações das participantes são grafadas em itálico no intuito de diferenciá-las das citações autorais. 
questōes" (Granville, 2008, p. 195). A segunda, a leitura-avaliação, faz-se habitual nas atividades destinadas à verificação da aprendizagem, principalmente nas provas e nas leituras paradidáticas. Essas práticas pouco contribuem para a formação do leitor proficiente, compreendido como

[...] aquele que sabe valer-se de estratégias metacognitivas para resolver as dificuldades que o texto lhe oferece, sejam elas de natureza léxica, sejam relacionadas à linguagem, sejam as suscitadas pela trama do texto, no caso da narrativa, sejam as necessárias a uma leitura subliminar ou leitura das entrelinhas (a do não-dito) do texto em questão (Granville, 2008, p. 196).

Reduzida à função informativa, a leitura não favorece o desenvolvimento de estratégias metacognitivas, dificultando a análise dos elementos presentes no texto, tornando custosa a elaboração de análise - pela identificação dos aspectos mais relevantes - ou de sínteses e, ainda, embaraçando um posicionamento crítico. O comprometimento da compreensão implica prejuízos para a formação do leitor.

Inicialmente, as alunas enfrentaram imensa dificuldade para identificar os conceitos-chave. Atinham-se às palavras interessantes ou desconhecidas, mas que raramente traduziam ideias fundamentais para a compreensão da totalidade das informações propostas no texto, mesmo porque não habituadas a avançar e retroceder no texto, pretendendo "[...] recuperar uma informação que ficou para trás [...]” (Granville, 2008, p. 196).

A leitura como aquisição de novos conhecimentos ou a leitura-fruição realizada pelo prazer inerente à atividade - são pouco frequentes no contexto escolar, pois subordinam-se à implantação de procedimentos didáticos favoráveis à compreensão do material impresso. Um desses procedimentos é o mapa conceitual.

Fundamentados na teoria da aprendizagem significativa de David Ausubel, os mapas conceituais são considerados instrumental importante para organizar e representar o conhecimento, pois evidenciam - por meio de proposições, ou enunciaçôes elucidativas - as conexôes estabelecidas entre ideias-chave (Novak, 1998). Neles, os conceitos são apresentados no interior de "caixas" ou alguma forma geométrica, enquanto as relaçōes entre eles são especificadas por linhas às quais são agregadas frases explicativas, que procuram aclarar relaçôes proposicionais significativas. Em consequência, para serem representados carecem de três elementos: conceito, proposição e "palavra(s) de enlace" (Novak, 1998, 2000; Ontoria, 1999, 2005, 2006; Moreira, 2006; Almeida, 2007).

A necessidade de localizar nos textos os conceitos-chave, aliada à possibilidade de confrontar as palavras destacadas com os pares e de estabelecer sua 
relevância em decorrência de sua manifestação reiterada, gerou nas alunas formas mais profundas de processar a informação, permeadas por idas e voltas, entremeadas por consulta em outros materiais informacionais: dicionários, livros, revistas e web. As observaçōes possibilitaram acompanhar a evolução das alunas. Também elas a perceberam, conforme descreve A2.

Inicialmente nós não conseguíamos identificar as palavras-chave.
Destacávamos tudo: palavras desconhecidas, palavras diferentes,
palavras curiosas. Mas, geralmente, palavras que diziam muito
pouco do principal do texto. Agora, não só para essa disciplina, mas
também para as outras, ficou mais fácil estudar, porque é quase
automático, leio o texto e vou grifando idéias principais com uma
cor e relacionando-as às palavras-chave, que grifo em outra cor,
para destacar.

A leitura não pode configurar-se apenas como a busca por "respostas certas" para "questōes pequenas". Ela deve envolver aspectos cognitivos, precisa abarcar os conhecimentos prévios do leitor, carece envolver discussões e partilha de perspectivas - tudo essencial ao entendimento do conteúdo do material.

Afora a identificação dos conceitos-chave, as alunas - $87 \%$ das duplas indicaram a hierarquização das ideias pelo estabelecimento entre elas de relações significativas, com sedimentação e integração dos conteúdos, como uma aprendizagem relevante. Os mapas são estruturas hierárquicas. Eles são principiados por conceitos mais abrangentes, aos quais vão sendo progressivamente relacionados conceitos mais específicos, esclarecendo as relaçôes de subordinação identificadas pelos educandos, evidenciando o grau e a qualidade de "abarcamento" que conseguem estabelecer entre conceitos com níveis de generalidade distantes ou aproximados (Novak, 1998, 2000). Tal método pressupõe o domínio do significado para além do destaque do significante (Ausubel; Novak; Hanesian, 1980). A composição vertical e descendente do mapa não se configurou uma tarefa singela para as alunas. A4 afirmou que:

[...] apesar de estarmos habituadas a realizar comparaçōes e criar hierarquias, principalmente como resultado do processo de avaliação da aprendizagem, quando precisamos pensar na disposição dos conceitos, o primeiro grande problema foi: "Qual o principal conceito? Qual o conceito mais geral e inclusivo? Mas, os problemas continuaram, pois todos os demais pareciam igualmente importantes.

Em um segundo momento, o alinhamento horizontal, intentando dispor uma "[...] representação mais completa das relações entre os conceitos" (Moreira, 2006, p. 46) e revelando a configuração da estrutura conceitual do aluno acer- 
ca da temática sob foco, constituiu tarefa complexa, conforme revelou A8: "separa e junta! Parece que viviamos de retirar conceitos do texto e juntá-los no mapa. Mas, esse juntar não era fácil, pois havia necessidade de hierarquizar (na vertical) e relacionar (na vertical e na horizontal)".

Outra aprendizagem indicada por percentual expressivo (75\%) foi o favorecimento de negociações de significados e de formas de estruturação dos mapas. A elaboração dos mapas, realizada ou finalizada em pequenos grupos, de certo modo, "obrigou" as alunas a compartilharem, discutirem e negociarem os significados atribuídos aos conceitos, a examinarem e debaterem as proposiçôes estabelecidas e as "palavras de enlace" escolhidas, até atingirem um razoável grau de concordância, gerando discussóes que animaram as aulas, aprofundando temáticas e suscitando a superação de problemas, conforme reconheceu A6: "As aulas eram mais gostosas quando construiamos os mapas, porque nos grupos nós discutíamos até entender cada um dos conceitos".

A construção de mapas e o compartilhar de significados e relaçôes com outros "[...] é uma atividade de estímulo ao pensamento reflexivo e à construção social do conhecimento. Os mapas conceituais podem, portanto, atuar como instrumentos para negociar significados" (Levy, 2000, p. 4), aproximando compreensões e favorecendo a expansão da rede de conhecimentos. Negociar significados é compartilhar e analisar compreensões, o que somente pode ser realizado quando se está com o outro, dialogando, "estabelecendo contrapontos de presenças e ausências, silêncios e falas, dúvidas e certezas, alegrias e conflitos [...]" (Caricatti; Guimarães, 2004, p. 96). Cada um que comparece à discussão - entendida como espaço de permutas e não de enfrentamentos - com a sua história de vida, com os seus conhecimentos prévios, intenta aprender e contribuir para a aprendizagem do outro, pois o objetivo é promover a superação das dificuldades e a progressão do "nós"; afinal, "o conhecimento deve ser concebido como fios que vão sendo puxados e tecidos criando novas significações, onde alguns irão conectar-se a novos, outros serão refutados ou serão ignorados pelos sujeitos, "nós", até que outros fios sejam tecidos a qualquer tempo/espaço na grande rede que é o próprio mundo" (Santos; Okada, 2003, p. 14).

Apesar de a aprendizagem implicar a elaboração e a reelaboração do conhecimento pelo educando, ela também permanece refém de interações com os pares e com o professor - que atuam na qualidade de mediadores, na tentativa de introduzir alterações nos conceitos prévios. A aprendizagem, a alteração de significados cognitivos, "[...] não podem ser transferidos ao estudante da forma em que se faz uma transfusão sanguínea. Para apreender o significado de qualquer conhecimento é preciso dialogar e compartilhar [...]" (Levy, 2000, p. 4) percepçōes e compreensões. 
No cerne das discussões e das confrontações, outra grande aprendizagem (38\%): a possibilidade de efetivar sucessivas síncreses, análises e sínteses, até porque, "a cada nova discussão era possivel aumentar a compreensão sobre o significado do conceito prévio, corrigir ou ampliar relaçôes antes estabelecidas, porque sempre havia conceitos novos a serem acrescentados [...]" (A4).

Aprender significativamente é "[...] uma expansão da rede de conhecimento (rede cognitiva) da pessoa, ocorrendo por meio de uma integração de novos conceitos e reestruturação das ligações entre conceitos previamente existentes na rede cognitiva" (Amabis, 2006, p. 2). Os conceitos prévios - síncreses -, portanto, são fundamentais para atuar como pontos de ancoragem para os novos conhecimentos. Estes favorecerão a diferenciação progressiva e a reconciliação integrativa daqueles em função dos novos elementos introduzidos - a subsidiarem as análises -, gerando novas formas de organizar o conhecimento - sínteses.

Os mapas conceituais, assim, evidenciam a ocorrência de uma reorganização cognitiva, porque os conceitos são estendidos em seus significados e as relações proposicionais são alteradas. Assim, vários conceitos específicos "[...] tendem a se reorganizar e a se interligar, formando novos conceitos e proposiçôes, tornando a estrutura do domínio cada vez mais refinada" (Struchiner; Vieira; Ricciardi, 1999, p. 61).

As salas de aula constituem espaços para a aprendizagem. Mas é preciso reconhecer que aprender é muito mais do que meramente acumular informações e conhecimentos, é um processo contínuo que aglutina as diferentes dimensões constitutivas do ser humano, preservando a herança legada pelo passado, valorizando as experiências advindas do presente e ampliando os sonhos que ensejam o futuro.

\subsection{Situando vantagens e dificuldades}

Sol e sombra compõem o dia. A percepção de um vincula-se à existência do outro, não pela contradição, mas pela interdependência e complementaridade. Da mesma forma, possibilidades e dificuldades compóem o cotidiano de todos e precisam ser reconhecidas e compreendidas, não como antagônicas, mas como frestas de possibilidade para uma ação mais consciente e efetiva.

As vantagens e as dificuldades advindas do emprego do mapa conceitual como instrumento avaliativo foram indicadas pelas alunas após discussões e reflexôes promovidas pelas duplas. Para tanto, elas retomaram os momentos vivenciados no passado, os registros de aula, os mapas elaborados. Vantagens e dificuldades diferem sem contrapor-se. Ambas são relevantes para a compreensão das possibilidades e dos óbices do mapa conceitual como instrumento para 
uma avaliação formativa, principalmente no que tange à compreensão das 32 alunas que o experimentaram no dia a dia de uma sala de aula.

As vantagens advindas da utilização do mapa conceitual como ferramenta avaliativa foram diversas: identificar as dificuldades de aprendizagem, orientando para aspectos a serem superados; favorecer a reelaboração de conceitos e sua consequente sedimentação, integração e ampliação dos conhecimentos; proporcionar feedback imediato ou quase imediato; possibilitar a autorregulação; tornar a atividade avaliativa estratégia de aprendizagem.

Identificar as dificuldades de aprendizagem, orientando para aspectos a serem superados, foi vantagem apresentada por todas as duplas respondentes. $\mathrm{Na}$ verdade, as práticas avaliativas efetivadas em uma perspectiva formativa não se resumem à atribuição de certos e errados, mas voltam-se para o que é importante, quando o compromisso é com a aprendizagem, pelo delineamento das pendências e subsequente promoção de intervençôes regulatórias. Desse modo, a avaliação deve estar a serviço das aprendizagens, deve estar comprometida com o êxito, deve ser capaz de "[...] compreender a situação do aluno [...], de fornecer-lhe indicações esclarecedoras [...], de preparar a operacionalização das ferramentas de êxito [...]" (Hadji, 2001, p. 8). Nessa perspectiva, os mapas conceituais apresentaram-se como instrumental adequado e oportuno, pois auxiliaram as alunas a aprender e a desenvolver-se, colaborando para a sua autorregulação.

"Os mapas conceituais tornam os nossos conhecimentos mais claros, no que sabemos ou não, porque evidenciam o que aprendemos, mostrando também as nossas dúvidas, dificuldades e erros", afirmou A2. Ainda A4 esclareceu: "[...] sempre que olhamos o nosso mapa e o comparamos com outro, nós podemos perceber semelhanças, diferenças e também identificar os erros".

Reconhecer os acertos e identificar os erros constituem ações igualmente importantes. Mas são os erros que permitem delinear o caminho que resta percorrer, afinal, nos erros estão os indicadores dos aspectos a serem superados e, então, não importa quantos tenham sido, mas interessa determinar a natureza e a qualidade que apresentam, principalmente porque "uma avaliação formativa deveria possibilitar a 'compreensão' da situação do aluno [...]" (Hadji, 2001, p. 98) por ele próprio, bem como pelo professor. Desse modo, longe de constituir um problema, o erro "[...] evidencia os conhecimentos apropriados, as aproximaçōes efetivadas em direção ao novo, as articulações estabelecidas entre as novas informaçóes e as anteriores, as tentativas empreendidas pelo educando por entre as possibilidades que se apresentam no decurso do processo de construção do saber" (Souza, 2006, p. 217).

Os erros são indícios a serem localizados e interpretados, afinal, é fundamental aos alunos avaliar suas dificuldades e suas ausências de conhecimento, 
objetivando superação. Quando emergem nos mapas, os erros evidenciam os equívocos conceituais - ou seja, dos conhecimentos envolvidos na tarefa -, bem como explicitam os processos desenvolvidos e o raciocínio que conduziram ao formato final conferido à estrutura.

Acerto e erro precisam ser identificados, pois faz-se fundamental determinar o conhecimento apropriado, como, também, aquele ainda em processo de aprendizagem - ou o que ainda não se sabe, mas pode-se vir a saber. "Não saber que não se sabe" é designado "ignorância secundária", conforme esclarece Brown (1978, apud Ribeiro, 2003, p. 110). Para saber o que se sabe, bem como o que não se sabe, há necessidade de proporcionar feedback imediato ou quase imediato - outra das vantagens indicadas por metade das duplas respondentes.

O erro não pode permanecer vinculado à ideia de fracasso, mas deve aliar-se à de possibilidade. Conforme Carvalho (1997, p. 12), a "[...] verdade emerge mais facilmente do erro do que da confusão", razão pela qual, talvez, "a aprendizagem não começa com a ignorância, mas com o erro". O acerto pode decorrer do acaso, mas o erro sempre advém de um bom motivo. Aclarar sua razão é dispor de indicadores na recomposição do ensino e da aprendizagem. No decorrer das atividades utilizando o mapa conceitual como ferramenta avaliativa, as alunas passaram a observar seus erros, percebendo-os como sinais merecedores de reflexão e subsequente regulação, afinal, "[...] não é suficiente saber que errou, é preciso também ter elementos para avaliar a qualidade do erro" (La Taille, 1997, p. 37) e, ainda, dispor-se a empreender os esforços essenciais à sua superação, aspecto que, aparentemente, foi apreendido pelas alunas.

Quando os mapas eram apresentados, a primeira coisa que indagávamos, olhando e comparando, era: Nós usamos os mesmos conceitos? Nós escolhemos o mesmo conceito-mãe? As relaçôes estabelecidas entre os conceitos são parecidas? O significado dos conceitos é próximo? Enquanto assistíamos às apresentaçôes, podiamos identificaro nosso erro e, também, podíamos repensar nossos conceitos e o nosso mapa a partir de pistas fornecidas pela colega. (A7)

O erro, progressivamente, deixou de ser razão de vergonha ou fonte de temor. Ele passou a constituir estratégia a contribuir na organização sequencial das açōes de professora e alunas, principalmente porque importava alcançar as metas educativas previstas. Por isso, a "[...] utilização do erro deve ser entendida como uma ferramenta conceitual da qual se necessita ante os conceitos específicos, como um veículo que encurta as distâncias entre intençôes e realizaçôes" (La Torre, 2007, p.10). Para A7, identificar seus erros e refletir acerca de suas razões possibilitou aprender, superando dificuldades pela recomposição 
das suas estruturas cognitivas: conceitos prévios foram sendo alterados - passo a passo, dia a dia - e novas proposições foram sendo elaboradas.

É interessante comparar o mapa que construimos individualmente com aquele que resultou do trabalho em grupo. Eu posso perceber minha evolução, porque o número de conexōes sempre aumenta e a qualidade das explicaçôes que ligam os conceitos também. Mas, essa mudança só é possivel porque nas discussōes e comparaçôes percebemos os erros e buscamos ajuda para superá-los. (A7)

$\mathrm{Na}$ identificação do erro e na compreensão das razões que o ensejaram, o mapa conceitual, utilizado como ferramenta avaliativa, configurou-se excelente estratégia de aprendizagem, conforme indicaram as alunas na enunciação de outra vantagem, principalmente porque "[...] nem mesmo lembrávamos de que os mapas eram para avaliação. Éramos avaliadas e nos avaliávamos não em função de uma nota, mas porque identificávamos os acertos e os erros. Os erros, nós buscávamos corrigir e, para mim, isso é aprender" (A5).

$\mathrm{O}$ processo de elaboração dos mapas e sua apresentação posterior ofereceram dados relevantes acerca dos conhecimentos e das habilidades formados ou em formação. $\mathrm{O}$ tratamento conferido a esses dados particularizou a ocorrência do compromisso formativo da avaliação: o mapa conceitual favoreceu o debate dos conceitos básicos da disciplina, bem como sua reelaboração, conferindo concretude à aprendizagem significativa ao propiciar discussões e confrontações entre os conhecimentos prévios dos educandos e os conceitos científicos sob foco.

Avaliar formativamente é investir na regulação do processo de aprendizagem, assegurando progressão continuada na apropriação do saber. A ferramenta mapa conceitual possibilita a valorização da bagagem trazida pelo educando, mas inspira o desvelamento e a compreensão mais aprofundada do que se pensava sabido, até porque "[...] a mudança conceitual não implica no abandono do que se sabe, pois os significados construídos são resultados de aprendizagem significativa, elas fazem parte da história cognitiva do indivíduo [...]. Essa história, além de ser única para cada indivíduo, é, provavelmente, “inapagável”" (Moreira, 1999, p. 174).

Selecionar os conceitos-chave, defini-los, discuti-los, organizá-los hierarquicamente, dispô-los em uma estrutura uni ou bidirecional, relacioná-los, elucidando a natureza dessa relação - sempre em um trabalho que vai do particular ao coletivo, retornando ao individual; bem como apresentar as produções confrontando conteúdo e forma, fomentou a elucidação dos significados dos conceitos, de maneira que o preexistente se transforma, conquistando significados adicionais, o que demanda "[...] um ensino explicitamente planejado para esta finalidade” (Moreira, 1999, p. 175). 
As alunas reconheceram a relevância da tarefa avaliativa na promoção da aprendizagem. Para A2, "[...] elaborar os mapas conceituais foi muito bom, porque nos obrigou a olhar o texto de outra forma e a retornar a ele muitas vezes. $\mathrm{Na}$ elaboração dos mapas, o interesse não era a nota, mas o que ainda tínhamos a aprender". Assim, o mapa conceitual como ferramenta avaliativa configurou-se, também, estratégia de aprendizagem, vantagem enunciada por $31 \%$ das duplas respondentes.

Uma avaliação formativa é, antes de tudo, informativa para aqueles que participam do processo. Não importa meramente determinar o grau de êxito alcançado, mas precisar, em decorrência dos problemas de aprendizagem constatados, as adaptaçōes a serem implementadas pelo aprendiz para aprender, até porque, "[...] as análises da avaliação formadora são essencialmente conduzidas em nome da busca de uma pertinência e de uma eficácia pedagógicas" (Hadji, 2001, p. 91).

A utilização do mapa conceitual como ferramenta avaliativa contribuiu, conforme esclareceu A6, para "[...] aprender a aprender, o que ficou muito claro quando passamos a usar o mapa conceitual em outras disciplinas. O mapa é um ótimo modo de estudar e de aprender". Assim, ele evidencia, também, seu potencial como estratégia de aprendizagem, enquanto, concomitantemente, configura-se instrumental para a coleta de dados a subsidiar o processo avaliativo.

A utilização do mapa conceitual permitiu às alunas "[...] identificar as lacunas de aprendizagem, os conceitos que ainda estavam confusos. Não pudemos nos acomodar e repetir o que estava escrito no livro, porque precisávamos recompor nossa compreensão em uma estrutura que fosse nossa" (A4). Sem dúvida, elas passaram a pensar mais sobre o que sabiam, sobre o que e como aprendiam, de forma a poder autorregular sua aprendizagem - outra vantagem enunciada por $75 \%$ das duplas respondentes. Afinal, na identificação dos erros e na determinação de sua natureza pelas próprias alunas, aliadas ao compromisso com a superação e a aprendizagem, reside o espaço para a autorregulação.

Autorregulação nada mais é que "[...] a capacidade do sujeito para gerir ele próprio seus projetos, seus progressos, suas estratégias diante das tarefas e dos obstáculos". Para que ocorra, "[...] supõe-se ser necessário ao aprendiz um motivo forte, de verdadeiros desafios que o sensibilizem profundamente, um desejo de saber e uma decisão de aprender" (Perrenoud, 1999, p. 97). Ainda na promoção de uma aprendizagem mais autorregulada, na perspectiva do processamento de informações, os mapas conceituais contribuem para "[...] a aquisição, o armazenamento e/ou a utilização da informação" (Boruchovitch, 1999, p. 3) e configuram-se, de acordo com as principais taxionomias, como estratégia cognitiva de organização do conhecimento, com importantes implicaçôes para o desenvolvimento da metacognição. Desse modo, a apropriação e a utilização dos mapas conceituais podem ajudar o estudante a autorregular-se, conforme 
lhe possibilite aprender a aprender e a exercer maior controle sobre seus procedimentos de aprendizagem (Boruchovitch, 2004; Silva; Simão; Sá, 2004; Jou; Sperb, 2006).

Os mapas mobilizaram as alunas, envolveram-nas, incitando-as à preparação de produções progressivamente mais elaboradas, à apresentação de estruturas mais abrangentes e inclusivas. Uma primeira elaboração demandava confrontos, discussões, análises, aprimoramentos, que geravam mais e mais aprendizagens enquanto se configuravam em novas elaboraçôes, em outros mapas. A3 afirmou: "Ao identificar os erros, corríamos atrás do prejuizo... Se o engano era conceitual, se as ligaçōes estavam equivocadas, nós buscávamos ajuda para aprender. As vezes, retomávamos o texto, outras vezes nós questionávamos a professora ou discutíamos com as colegas".

A autorregulação constitui "[...] uma dimensão fundamental dos processos cognitivos, estando forçosamente presente em todo momento em cada aprendiz" (Allal, 1983, p. 86). Envolve a "tomada de consciência" quanto à importância de aprender a lançar um olhar retrospectivo sobre os próprios passos, compreendendo-os e alterando-os para assegurar a superação dos obstáculos e o avançar progressivo no domínio dos saberes. Desse modo, investir na superação dos erros, inclusive pela autorregulação, favoreceu a reelaboração de conceitos, sua apropriação, sedimentação, integração e ampliação pelas alunas, mais um dos benefícios advindos da utilização dos mapas como instrumentos avaliativos (44\%).

As restrições ou perdas nunca são esperadas ou desejadas. Entretanto, elas são concretas - em sua imaterialidade - e constituem o real como contraponto, a incitar a reflexão e o aperfeiçoamento. Enunciá-las não é depreciar um momento ou minimizar a importância de uma vivência, mas buscar novos espaços de crescimento e superação. As alunas foram quase unânimes nos quatro aspectos que indicaram como limitações para a utilização do mapa conceitual: identificar e harmonizar conceitos; escolher palavras de enlace apropriadas; construir o mapa; e demandar confrontações.

Identificar e harmonizar os conceitos foram aspectos apresentados como desvantagem na utilização dos mapas como instrumentos avaliativos por todas as duplas respondentes, mesmo porque "[...] não aprendemos a ler identificando aspectos realmente essenciais ou centrais em um texto, nem a selecionar termos importantes ou significativos para a compreensão do todo, o que é fundamental para a elaboração dos mapas" (A8).

Apesar de este haver sido um dos aspectos enunciados como aprendizagem conquistada, não deixou de ser uma dificuldade, principalmente porque não bastava identificar os conceitos, mas harmonizá-los, hierarquizando-os e relacionando-os com o uso de conectores acompanhados das "palavras de enlace" ou 
descritores (Novak, 1998, 2000). A2 destacou esse aspecto ao afirmar: "Os mapas tinham que ser claros, apresentando os conceitos hierarquicamente distribuidos e relacionados de modo que a sua 'leitura' fosse clara e precisa. Os significados dos conceitos e das relaçôes precisavam ficar claros".

Possivelmente, essa tenha sido a razão para que a tarefa de escolher "palavras de enlace" que efetivamente definissem a relação entre os conceitos fosse outra das dificuldades indicadas (94\%). Não são quaisquer palavras que podem ser utilizadas, mas precisam ser as palavras certas para traduzir a compreensão acerca da inter-relação existente entre os conceitos interligados, conforme revelou A4: "Não era fácil encontrar as 'palavras de enlace'. Às vezes, tínhamos certeza da relação entre dois ou mais conceitos, mas não conseguiamos dizer isso, não conseguiamos escrever isso deixando claro para quem lesse".

A construção de mapas é mais que o delineamento de diagramas ou organogramas, até porque exige a elucidação da natureza e da qualidade das relaçōes existentes entre os conceitos priorizados. Por isso, "[...] os mapas conceituais têm a ver com relaçôes significativas entre conceitos na forma de proposiçōes" (Moreira, Buchweitz, 1993, p.18), sendo estas compreendidas como conceitos interligados por linhas acompanhadas de explicaçóes que elucidam a natureza da relação. Essas explicações constituem unidades semânticas que apresentam "[...] um valor de verdade, uma vez que afirmam ou negam algo de um conceito" (Ontoria et al., 1999, p. 31).

Construir o mapa, explicitando o processo cognitivo vivenciado na apropriação do conhecimento, foi outra das desvantagens indicadas (81\%), talvez porque os mapas devam apresentar os conceitos de maneira a evidenciar o grau de importância e de especificação na própria estrutura hierárquica elaborada. Ultrapassando a definição das palavras-chave, engloba as inter-relações estabelecidas entre elas, o que exige uma compreensão progressivamente mais ampla e profunda da temática sob foco.

Os mapas constituem sínteses ou resumos elaborados para destacar o que efetivamente foi mais relevante em um contexto informacional. Desse modo, eles apresentam sempre um "quê" de subjetividade, decorrente da pessoalidade da abordagem da temática e da particularidade dos conceitos prévios disponíveis na estrutura cognitiva.

Outra dificuldade enunciada foi a necessidade de confrontação de produções para identificação de erros ou equívocos (25\%). Cada mapa é revelador de uma "leitura", de um momento do processo de aprendizagem. Mas aprender é um processo contínuo, composto por uma sucessão infindável de "leituras", intercaladas por paradas reflexivas que permitem contemplar o conquistado e delinear o ainda a ser perseguido. Esta é uma tarefa exigente e cansativa, principalmente quando as informações são, em princípio, de natureza qualitativa. 


\section{Tecendo fios e elaborando algumas considerações}

Os mapas são úteis na organização da aprendizagem e na demonstração do conteúdo e forma do apropriado em relação a um tópico ou a um conteúdo. Eles possibilitam, portanto, a percepção de como uma determinada informação é incorporada e passa a integrar a organização geral dos conhecimentos. Para Novak (2000, p. 192), “[...] o mapa se torna uma importante experiência de aprendizagem, bem como uma avaliação única”.

Utilizados como instrumentos para a avaliação da aprendizagem em uma perspectiva formativa, os mapas conferem visibilidade aos processos cognitivos e metacognitivos empreendidos pelo aluno para a apropriação dos conceitos, constituindo "[...] um instrumento simples que permite logo ao professor 'saber onde está o aluno"” (Moreira, Buchweitz, 1993, p. 58), facultando-lhe, portanto, uma "melhor compreensão do 'funcionamento do aluno" (Hadji, 2001, p. 23).

Os mapas conceituais cumprem uma importante função quando empreendidos como instrumento avaliativo: fornecem informaçōes para alunos e professores, permitindo-lhes correções e adaptações essenciais à aprendizagem e ao desenvolvimento. Desse modo, favorecem uma avaliação menos preocupada com aspectos quantitativos e mais voltada para a promoção de retornos de informação aos alunos. Mas esses são apenas alguns dos ganhos advindos da utilização do mapa conceitual. Acrescentam-se a eles: o desenvolvimento metacognitivo e o favorecimento dos processos autorregulatórios de aprendizagem. Aspectos essenciais - todos esses - à consecução do processo educativo, sobretudo quando este está destinado à formação de um futuro professor (Boruchovitch, 2006).

As aprendizagens decorrentes de seu uso são numerosas, não se limitando à apropriação dos saberes envolvidos na construção dos mapas. As alunas situaram-nos: aprenderam a enfocar o essencial, identificando conceitos-chave; aprenderam a hierarquizar ideias, estabelecendo relaçóes significativas entre elas, sedimentando e integrando conteúdos; aprenderam a favorecer a negociação de significados e formas de estruturação; e, ainda, aprenderam a estabelecer novas e progressivas síncreses-análises-sínteses.

Vantagens e dificuldades emergiram e impuseram-se a cada nova vivência utilizando o mapa conceitual como instrumento para uma avaliação formativa. Mas ambas - vantagens e dificuldades - complementam-se quando percebidas; aquelas, como possibilidade de ação e, estas, como espaço de superação.

As vantagens enunciadas pelas alunas evidenciam o cuidado com que contemplaram os passos que deixaram impressos no solo ao longo de sua caminhada: identificar as dificuldades de aprendizagem, orientando para aspectos a 
serem superados; favorecer a reelaboração de conceitos e sua consequente sedimentação, integração e ampliação dos conhecimentos; proporcionar feedback imediato ou quase imediato; possibilitar a autorregulação; e, também, tornar a atividade avaliativa uma atividade de aprendizagem, especialmente pelas confrontaçôes que proporcionou.

As dificuldades indicadas não foram menos importantes, apenas evidenciaram aspectos que precisam ser mais constante e profundamente trabalhados: identificar e harmonizar os conceitos; escolher "palavras de enlace" que efetivamente definam a relação entre os conceitos; construir o mapa explicitando o processo cognitivo vivenciado na apropriação do conhecimento; e, também, demandar confrontação para identificação dos equívocos. Contudo, é preciso reconhecer que a vida é feita de contrastes e que, ao lançar um olhar mais profundo sobre as dificuldades apontadas, é possível constatar que, na verdade, elas assumiram sabor de desafio, mesmo quando suscitaram: inquietação, sofrimento e desestruturação dos percursos já trilhados. Subjazendo a tudo - dificuldade e desejo de ir além -, a motivação para o enfrentamento, a motivação para a superação dos percalços, que se revelou na alegria de poder constatar que uma dificuldade se transformou em aprendizagem, que o que é difícil não é impossível, que uma estratégia de ensino/aprendizagem/avaliação pode contribuir decisivamente para a alteração da situação de ainda não saber, para outra na qual os ganhos qualitativos podem ser claramente identificados na aprendizagem e no desenvolvimento dos educandos.

Apesar de afigurar-se extremamente produtiva, a utilização dos mapas como instrumento avaliativo não é uma tarefa tão fácil. As dificuldades estão presentes, assim como as possibilidades que oferecem àqueles que decidem colocar a avaliação a serviço das aprendizagens.

\section{Referências bibliográficas}

ALLAL, L. Régulations métacognitives: quelle place pour l'élève dans l'évaluation formative? In: ALLAL, L.; BAIN, D.; PERRENOUD, P. (Ed.). Evaluation formative et didactique du français. Neuchâtel: Delachaux \& Niestlé, 1983. p. 81-98.

ALMEIDA, L. R. M. Avaliação formativa no contexto da construção do mapa conceitual. Sitientibus, Feira de Santana, n. 36, p. 175-195, jan./jul. 2007. Disponível em: <http:// www.uefs.br/sitientibus/pdf/36/avaliacao_formativa_no_contexto_da_construcao_do_ mapa_conceitual.pdf>. Acesso em: 10 jan. 2009.

ÁLVAREZ MÉNDEZ, J. M. Avaliarpara conhecer. Examinar para excluir. Porto Alegre: Artmed, 2002.

AMABIS, J. M. Mapeando conceitos. 2006. Disponível em: <http://www.sembio.ufba.br/ material/1Mapeamento\%20de\%20conceitos.pdf>. Acesso em: 28 jan. 2007. 
ANDRÉ, M. E. D. A. de. Etnografia da prática escolar. Campinas, SP: Papirus, 1995.

AUSUBEL, D. P.; NOVAK, J. D.; HANESIAN, H. Psicologia Educacional. Rio de Janeiro: Interamericana, 1980.

ARAÚJO, A. M. T.; MENEZES, C. S. de; CURY, D. Apoio automatizado à avaliação da aprendizagem utilizando mapas conceituais. In: SIMPÓSIO BRASILEIRO DE INFORMÁTICA NA EDUCAÇÃO - NCE, 14., Rio de Janeiro, 2003. Disponível em: <http://www.nce.ufrj.br/sbie2003/publicacoes/paper31.pdf>. Acesso em: 5 out. 2009.

BARBOSA, M. L. et al. Mapas conceituais na avaliação da aprendizagem significativa. In: SIMPÓSIO NACIONAL DE ENSINO DE FÍSICA, 16., Curitiba, 2005. CD ROM. Disponível em: <http://www.sbf1.sbfisica.org.br/eventos/snef/xvi/sys/resumos/T0028-2.pdf>. Acesso em: 5 out. 2009.

BAUER, M. W.; GASKELL, G. Pesquisa qualitativa com textos, imagens e sons: um manual prático. Petrópolis, RJ: Vozes, 2002.

BORUCHOVITCH. E. A psicologia cognitiva e a metacognição: novas perspectivas para o fracasso escolar brasileiro. Tecnologia Educacional, v. 22, n. 110-111, p. 22-28, 1993.

BORUCHOVITCH. E. Estratégias de aprendizagem e desempenho escolar: considerações para a prática educacional. Psicolologia: reflexão e crítica, Porto Alegre, v. 12, n. 2, 1999. Disponível em: <http://www.scielo.br/scielo.php?pid=S010279721999000200008\&script=sci_arttext\&tlng=pt>. Acesso em: 10 dez. 2008.

BORUCHOVITCH. E. A auto-regulação da aprendizagem e a escolarização inicial. In: BORUCHOVITCH, E.; BZUNECK, J. A. (Org.). Aprendizagem: processos psicológicos e o contexto social da escola. Petrópolis, RJ: Vozes, 2004. p. 55-88.

BORUCHOVITCH. E. Estratégias de aprendizagem: uma análise à luz das variáveis demográficas e motivacionais. Tese (Livre Docência) — Faculdade de Educação, Universidade Estadual de Campinas, Campinas, 2006.

BRONSON, M. B. Selfregulation in Bearly Childhood. New York; London: Guilfor Press, 2000.

CARICATTI, A. M. C.; GUIMARÃES, L. de T. Revisitando o grupo. In: SPARTACO, M. (Org.). Os procedimentos de ensino fazem a aula acontecer. São Paulo: Avercamp, 2004.

CARVALHO, J. S. F. de. As noções de erro e fracasso no contexto escolar: algumas consideraçōes preliminares. In: AQUINO, J. G. (Org.). Erro e fracasso na escola: alternativas teóricas e práticas. São Paulo: Summus, 1997. p. 11-24.

GRANVILLE, M. A. Práticas de leitura no contexto escolar. In: GRANVILLE, M. A. (Org.). Sala de aula: ensino e aprendizagem. Campinas, SP: Papirus, 2008.

HADJI, C. A avaliação desmistificada. Porto Alegre: ArtMed, 2001.

JOU, G. I. de; SPERB, T. M. A metacognição como estratégia reguladora da aprendizagem. Psicologia: Reflexão e Crítica [online]. v. 19, n. 2, p. 177-185, 2006. ISSN 0102-7972. Disponível em: <http:/www.scielo.br/scielo.php?pid=S0102-79722006000200003\& script=sci_abstract\&tlng=pt $>$. Acesso em: 10 abr. 2008. 
LA TAILLE, Y. O erro na perspectiva piagetiana. In: AQUINO, J. G. (Org.). Erro e fracasso na escola: alternativas teóricas e práticas. São Paulo: Summus, 1997. p. 25-44.

LA TORRE, S. de. Aprender com os erros: o erro como estratégia de mudança. Porto Alegre: Artmed, 2007.

LEVY, M. I. C. A questão da representação no ensino de ciências. In: CONGRESSO IBEROAMERICANO DE FORMAÇÃO DE PROFESSORES. Santa Maria, RS. 2000. Disponível em: <http://forrester.sf.dfis.furg.br/mea/remea/anais3/artigo14.htm>. Acesso em: 25 nov. 2006.

MARTINEZ-MUT, B.; GARFELLA, P. A construção humana através da aprendizagem significativa: David Ausubel. In: MINGUET, P. A. (Org.). A construção do conhecimento na educação. Porto Alegre: ArtMed, 1998. p. 127-148.

MOREIRA, M. A.; BUCHWEITZ, B. Novas estratégias de ensino e aprendizagem: os mapas conceptuais e o Vê epistemológico. Lisboa: Plátano, 1993.

MOREIRA, M. A. Teorias de aprendizagem. São Paulo: EPU, 1999.

MOREIRA, M. A. A teoria da aprendizagem significativa e sua implementação em sala de aula. Brasília: Editora Universidade de Brasília, 2006.

NOVAK, J. D. Aprendiendo a aprender. Barcelona: Marínez Roca, 1998.

NOVAK, J. D. Aprender criar e utilizar o conhecimento: mapas conceituais como ferramentas de facilitação nas escolas e empresas. Lisboa: Plátano, 2000.

ONTORIA, A. et al. Mapas conceptuais: uma técnica para aprender. Lisboa: Asa, 1999.

ONTORIA, A. et al.. Mapas conceituais: uma técnica para aprender. São Paulo: Loyla, 2005.

ONTORIA, A. et al.. Aprender com mapas mentais: uma estratégia para pensar e estudar. São Paulo: Madras, 2006.

OTSUKA, J. L. et al. Suporte à avaliação formativa no ambiente de educação à distância TelEduc, Campinas, 2002. Disponível em: <http://www.teleduc.org.br/artigos/18_jrth_ie2002.pdf>. Acesso em: 5 out. 2009.

PERRENOUD, P. Avaliação: da excelência à regulação das aprendizagens - entre duas lógicas. Porto Alegre: Artmed, 1999.

RIBEIRO, C. Metacognição: um apoio ao processo de aprendizagem. Psicologia: Reflexão e Crítica, [online]. 2003, v.16, n.1, p. 109-116. ISSN 0102-7972. Disponível em: <http:// www.scielo.br/pdf/prc/v16n1/16802.pdf>. Acesso em: 1 abr. 2009.

SANTOS, E. O. dos; OKADA, A. L. P. A imagem do currículo: da crítica à mídia de massa a mediação de autorias dialógica na prática pedagógica. 2003. Disponível em: <http:// people.kmi.open.ac.uk/ale/journals/r01faeba2003.pdf>. Acesso em 1 abr. 2009.

SAKAGUTI, T. S. Mapas conceituais e seus usos: um estudo da literatura. Campinas, 2004. Dissertação (Mestrado Profissional em Engenharia da Computação) - Universidade Estadual de Campinas, Campinas. Disponível em: < http://libdigi.unicamp.br/document/ ?code $=v t l s 000332759>$. Acesso em: 5 out. 2009. 
SILVA, A. L. da; SIMÃO, A. M. V.; SÁ, I. A auto-regulação da aprendizagem: estudos teóricos e empíricos. Intermeio, Campo Grande, v. 10, n. 19, jan./jun. 2004. Disponível em:<http:// www.propp.ufms.br/poseduc/revistas/intermeio/intermeio19.html>. Acesso em: 12 jul. 2008.

SOUZA, N. A. A função pedagógica do erro. In: CONGRESSO INTERNACIONAL EM AVALIAÇÃO EDUCACIONAL, 3., Fortaleza: ABAVE, 2006. p. 215-246. CD-ROM.

STRUCHINER, M.; VIEIRA, A. R.; RICCIARDI, R. M. V. Análise do conhecimento e das concepçóes sobre saúde bucal de alunos de odontologia: avaliação por meio de mapas conceituais. Cadernos de Saúde Pública, Rio de Janeiro, n. 15 p. 55-68, 1999. Sup.2.

Recebido em 27 de maio de 2009 e aprovado em 05 de novembro de 2009. 